\title{
Mitt nepalske øye
}

\author{
I oktober 2014 ble jeg operert for grå stær på Geta Eye Hospital vest i Nepal av øyelege Suresh Raj Pant. \\ Bakgrunnen for dette noe spesielle valg av operasjonssted var landets imponerende satsing på øyehelse, \\ og et eksempel på godt fungerende norsk helsebistand gjennom 30 år.
}

Mons Lie

mons.lie@online.no

Nepal er et av verdens fattigste land, halvparten så stort som Norge og med 30 millioner innbyggere, hvorav en firedel lever under fattigdomsgrensen (1). I 1980-81 utførte WHO, sammen med regjeringen i Nepal, en omfattende undersøkelse av øyehelsen i landet. De fant at $0,84 \%$ av befolkningen var blinde og at $80 \%$ av årsakene kunne behandles. Blindhet skyldtes grå stær og trakom i hhv. $72 \%$ og 2,4\% av tilfellene (2). På grunnlag av disse funnene startet regjeringen i Nepal et program, Vision 2020, for forebygging og behandling av blindhet $i$ landets vestlige region (3). Geta-sykehuset i landsbyen av samme navn i Kailali-distriktet ble etablert med støtte fra Norad (4, s. 123-32).

Den norske øyelegen Albert Kolstad (f. 1929) deltok i undersøkelsen i 1981 og var helt fra starten den faglige drivkraften bak dette sykehuset. Han bodde i telt under primitive forhold, brukte selvlagede kniver av barberblad, lokalt snekrede stativ til mikroskop og kryoprober, der han utnyttet brukte gassflasker fra fjellklatrerne, til ekstraksjon av linsen. Han utdannet lokale landsbyboere til assistenter og etter hvert selvstendige operatører (4, s. 123-32). Mange av disse fikk senere bekostet utdanningen til leger og andre spesialfunksjoner, og det er disse lokale kreftene som danner hele infrastrukturen i sykehuset. I ti år bodde Kolstad mer eller mindre sammenhengende i Geta, bygde eget hus og ble i 1987 æresmedlem av Nepals øyelegeforening (4, s. 97). Han fikk hjelp av noen norske øyeleger som tjenestegjorde i tre måneders turnus i Geta. Dag Riise kom $i$ alt fire ganger og var en stor støtte. Bildet av Kolstad og Riise henger på veggen i sykehusets møterom, sammen med et bilde av Inger (1912-94) og Finn Lie (1912-99) som ga hele grunnkapitalen til en stiftelse for bekjempelse av blindhet, InFiL (for Inger og Finn Lie). Stiftelsen har vært en viktig finansiell støttespiller i prosjektet.

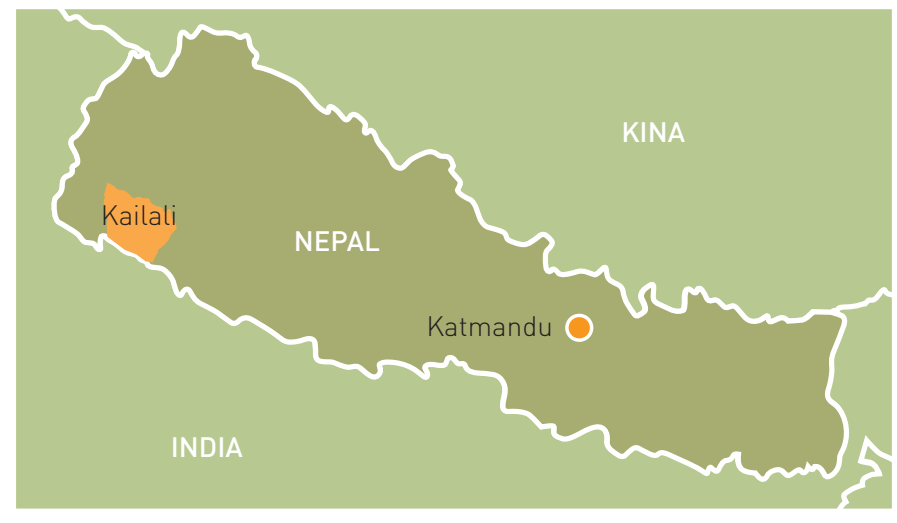

\section{Landets satsing på øyehelse}

Geta øyesykehus er nå et selvstendig ideelt, selvfinansiert foretak under den nepalske paraplyorganisasjonen Nepal Netra Jyoti Sangh (National Society for Comprehensive Eye Care), som fra Katmandu overvåker alle landets øyehelseprosjekter og er direkte underlagt regjeringen $(4,5)$. Som styremedlem i InFiL var jeg nylig på et to ukers besøk i Nepal, hovedsakelig for å besøke Geta sykehus og for å diskutere finansieringstiltak som forbedring av vannog kloakksystemet, vedlikehold og støtte til stedets blindeskole. Vi startet i Katmandu med møte på kontoret til Sailesh Kumar Mishra, programdirektør for Nepal Netra Jyoti Sangh. Han ga oss en oversikt over utviklingen av øyehelsen i landet siden WHO-undersøkelsen.

Før 1980 ble det operert 800 øyepasienter årlig, og ventelisten var på ett år. Nå opereres det 300000 pasienter i året på landets 14 øyesykehus, og noen også ved de 55 øyesentrene. $2 / 3$ av pasientene som opereres i dag kommer fra India. Det er ingen ventetid. Landet har 175 øyeleger, $95 \%$ utdannet i Nepal. Regjeringens mål er å få 800 øyespesialister. Forekomsten av blindhet er nå redusert til 0,34\%,53\% forårsaket av grå stær og $0,6 \%$ av trakom. Målet er å redusere forekomsten av blindhet i landet til 0,2\%(5).

\section{Landet, religion og befolkning}

Vi så utrolige soloppganger over Himalayas snøkledde topper på over 8000 meter både i Katmandu og i Pokhara. Derfra bilte vi over et vilt og forrevent fjellpass sørover til hovedveien som går i lavlandet øst-vest i hele Nepals 884 kilometers lengde. Vi overnattet i Lumbini, der Buddha ble født $i$ år 623 før Kristus. Ved inngangen til hans fødested står følgende sitat:

«No one can save us but ourselves, No one will or may We must ourselves walk the path»

Det er tankevekkende at i dette Buddhas fødeland er $11 \%$ av befolkningen buddhister, mens $80 \%$ er hinduer, $4 \%$ muslimer og $0,2 \%$ er kristne (1). De to største religionene lever tilsynelatende godt og harmonisk sammen. Landet har aldri hatt religiøse kriger og har aldri vært kolonisert. Hinduisme var tidligere statsreligion, men nå er både statsreligion og kongedømme avviklet og Nepal er en sekularisert republikk. Befolkningsveksten som tidligere var på $2,2 \%$ er nå på $1,4 \%$. Prevensjon er gratis og abort legalisert og gratis i svangerskapets 12 første uker. $65 \%$ av befolkningen kan lese og skrive og forventet levetid er 66 år (1).

\section{Geta øyesykehus}

Vi kom frem til Geta sykehus like etter solnedgang og ble i mørket sluppet inn av vakten gjennom den store dobbelte jernporten til et inngjerdet sykehusområde. Et utall av små bål under tak langs sykehusmuren ga, i tillegg til de elektriske lampene, et svakt skinn over pårørende og pasienter 


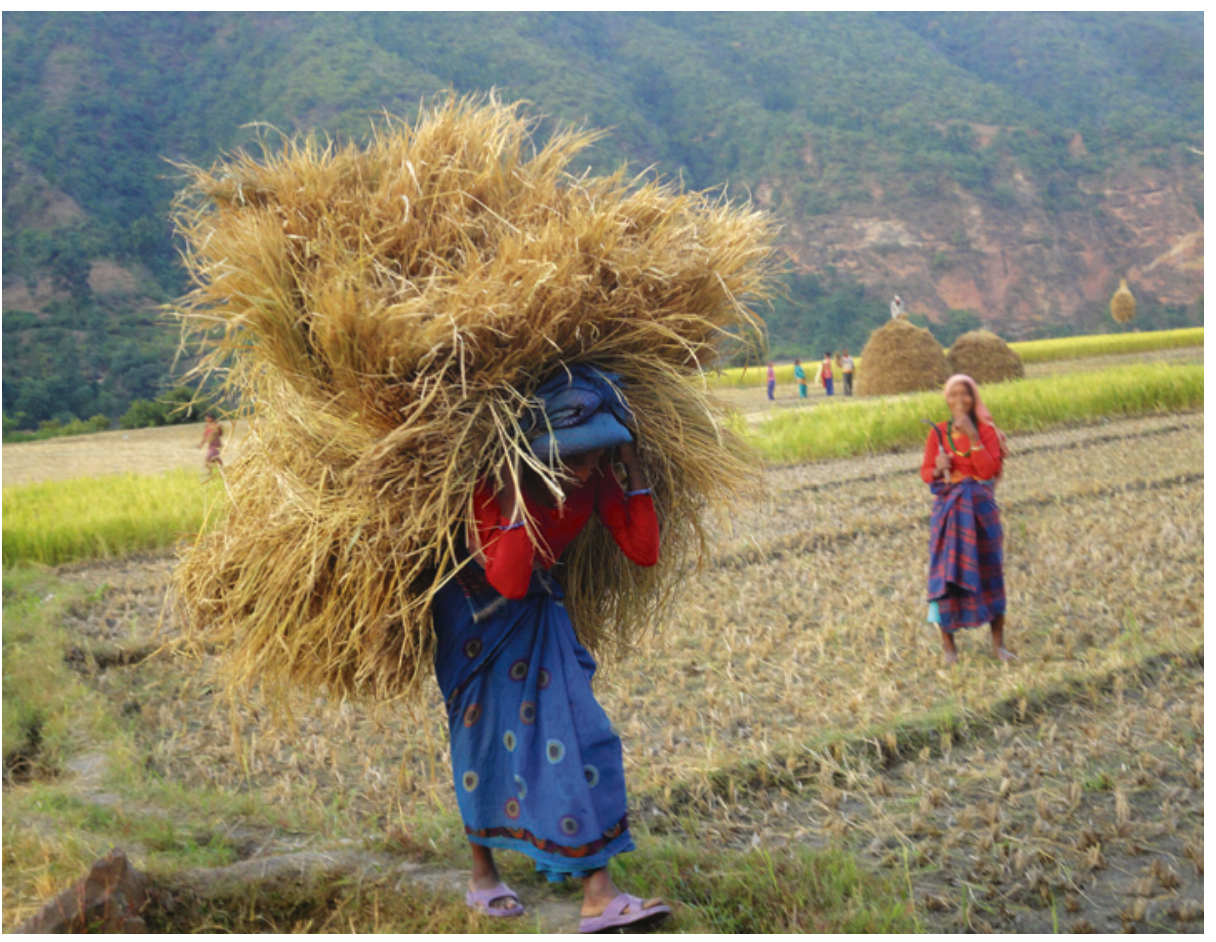

Kvinne som bærer risavling fra jordet. Foto: Mons Lie

som kokte maten sin og sov under ulltepper på det harde betonggulvet. Sovende gatehunder flyttet seg langsomt for billyktene der vi ble kjørt til vår bolig, en tre etasjers bygning med leiligheter til besøkende. Neste morgen kunne vi ta hele sykehusområdet i øyesyn, vist rundt av vår reisefelle, InFiLs leder, Svein Lie, som er sønn av Inger og Finn Lie. Han har fulgt dette prosjektet fra starten.
Sentralt er registreringsbygningen med køordning til de flere hundre pasientene som daglig møter opp til kirurgisk behandling uten å ha forhåndsbestilt. Alle pasientene får journal som blir oppbevart i sykehusets arkiv. Derfra går de over til den nye sentralblokken med stor ventehall, undersøkelsesrom og gang over til operasjonsfløyen med anestesirom med 15 benker der en mann kontinuerlig setter lokal øyeanestesi. Her

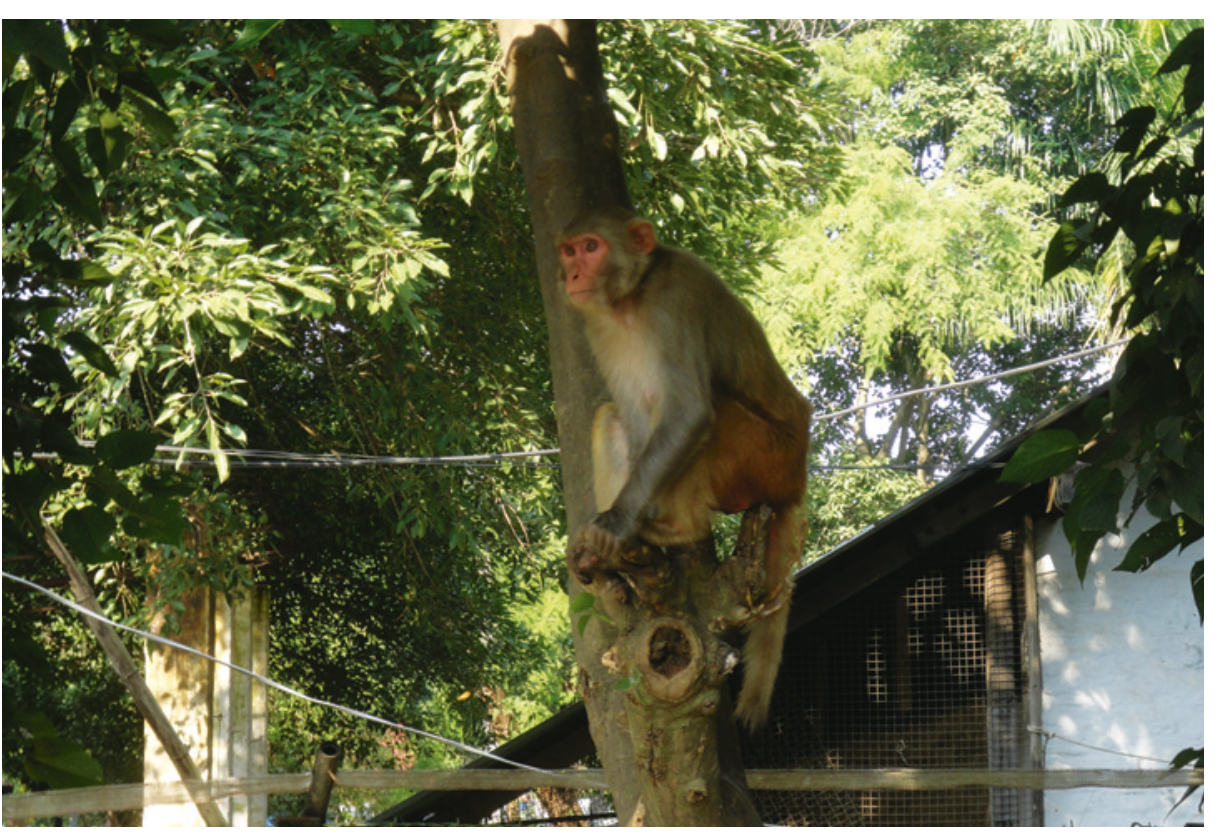

Apekatt på sykehusområdet. Foto: Mons Lie er to operasjonsstuer, den ene med fire bord, den andre med ett. I samme bygning er det stor sengeavdeling der pasientene ligger en natt etter operasjonen og der de blir tilsett av operatøren neste morgen. Her blir de stelt av pårørende som også gir dem mat, men som må sove ute ved sine små bål. Det er anledning til å få eget rom med sengebenk også til pårørende, men det koster 200 rupier, 12 norske kroner. Det slående er alle apekattene mellom pasientene og de pårørende - og så løshundene, magre med bedende blikk mot enhver matmulighet mens de klør seg i den skabbete pelsen. Apekattene er mer livsdyktige der de lekende lett beveger seg fra bakken til de store trærne, hunnene med ungene hengende på mage eller rygg, hannene majestetisk vandrende med sin store kjønnsprakt. Også disse på stadig jakt etter noe spiselig mellom de matlagende pårørende. Forsøket på å holde apekattene borte ved hjelp av elektrisk tråd rundt hele gjerdet har vært et foreløpig helt mislykket norsk prosjekt.

Vi startet morgenen i møte med sykehusets ledelse. De opererte i fjor 43768 pasienter, inkludert de som ble operert ved øyeklinikkene i distriktet (6). Sykehuset er Nepals neststørste øyesykehus og det eneste som har status «Center of Exellence». Staben er på 140, 90 på sykehuset i Geta, resten på øyeklinikkene. Omtrent $60 \%$ av pasientene kommer fra India. I tillegg til grå stær, opererer de grønn stær, skjeling og skader. De utfører også øyelokksplastikk og i fjor 39 hornhinnetransplantasjoner. Hornhinnene får de fra en hornhinnebank i Katmandu, dit de også sender selvhøstede hornhinner. De har nå planer om å opprette egen slik bank i Geta. Sykehuset driver 11 øyeklinikker blant fattige i fjellområdet i regionens ni distrikter. Her er det stedlig stab som diagnostiserer øyesykdommer og sender de pasientene som kan betale til Geta. Pasientene må betale 240 kroner for fast linse, 640 kroner hvis de blir operert med faco og myk linse. Kommer det pasienter uten penger, făr de likevel operasjon. To til tre ganger i året reiser øyeleger fra Geta med fullt team og utstyr til øyeklinikkene der de opererer enten på distriktssykehus eller skoler i nærheten. De som opereres der får dette gratis (6).

\section{Operasjonsstuen}

Etter møtet var vi på operasjonsstuen der to øyeleger den dagen opererte 112 pasienter for grå stær. Slutten av uken var det nasjonal helligdag og fri over hele landet. Derfor var det så få pasienter denne dagen. Vanligvis operer de 200-300 pasienter om dagen, rekorden er 500 (Suresh Ray Pant, personlig meddelelse). De har arbeidstid kl 9-17, seks dager i uken, men holder på 
til de er ferdige. Noen ganger kan klokken bli både 22 og 23 før siste pasient er operert. Legene får ikke overtidsbetaling eller avspasering, resten av staben får betalt for overtid. Vi så både faco med implantering av myk linse og «smal incision cataract surgery» med implantering av fast linse. Ingen av operasjonene krever sutur av hornhinnefestet. Der de brukte faco, var det bare ett operasjonsbord. I det andre rommet hadde hver kirurg to bord der han kunne svinge mikroskopet fra det ene til det andre. En operasjonsassistent ved hvert bord gjorde klart med skifte av pasient og preparering av operasjonsfeltet. Operasjonstiden var 3-5 minutter per pasient. Alt teknisk utstyr var topp moderne. Jeg sto lenge og fulgte Suresh Raj Pant og ble imponert over hans ro, hans økonomi i bevegelser, samarbeidet med operasjonsassistentene og hans skånsomme behandling av øyevevet. De fleste han opererte hadde moden katarakt med helt hvite linser og måtte være helt blinde. Han selv, 39 år gammel, er født i en liten landsby oppe i fjellene, nesten to timers gange fra bilvei. Han studerte medisin i Bangladesh og spesialiserte seg i øyesykdommer i Nepal. Han har operert 60000 øyepasienter og er visedirektør på Getasykehuset.

\section{Besøk på øyeklinikker i fjellene} Dagen etter kjørte vi opp i fjellene på en smal og svinget vei skåret inn i fjellsiden med stup på flere hundre meter rett ned. Et vilt og forrevent landskap med hyller med rismarker helt til topps drevet med håndmakt eller noen steder okser eller vannbøfler, små veiløse landsbyer eller bosetninger i de bratte fjellsidene. Og langs veiene kvinner som bar utrolig tungt på ryggen med bånd rundt pannen; store bunter med ris fra åkrene, ved, melsekker eller de hadde krukker på hodet. Alt ble båret, og alltid av kvinner, aldri et trekkdyr eller en traktor. Også skolebarn i uniform vandret langs veien. Og så bussene, fullstappede inni og med folk på taket og hengende på utsiden, blandet med tungt lastede trailere på altfor smale veier fylte av geiter, kuer og barn. Her oppe i disse fjellene var altså Suresh Raj Pant født. Vi besøkte to øyeklinikker, fire og seks timers kjøring fra Geta, og overnattet på et lite landsbyhotell mellom besøkene.

Om kvelden sluttet ledelsen fra Geta seg til oss. De skulle ha byggemøte ved den siste øyeklinikken der de bygger et nytt øyesykehus som skal dekke distriktet rundt med permanent øyekirurgi betjent av stab fra Geta. Hit kom også Suresh Pant, som ba oss med til tempelet før vi besøkte øyeklinikken. Vi gikk sammen opp trappen mot tempelet med alle de underlige figurene med menneske- og dyrehoder på begge sider. Vi tok av oss skoene og entret tempelet med svastikaen malt på veggen ved inngangen. Dette tusenår gamle symbol som betyr lykke og som hos oss i Europa for alltid er blitt så ugjenkallelig vanæret. Inne i det lille røkelsesfylte rommet malte en prest en rød stripe i pannen vår og velsignet oss. Ingen gudstjeneste eller forkynning. Alle figurene er guder. «Vi har hundrevis av dem», sa Suresh med et smil. «For oss er sjelen udødelig og gjenfødes i dyr eller mennesker. Har du levet rett, får din sjel en god bolig i neste liv. Etter døden må vi brennes ved en elv og så må asken strøs på elvevannet. Uansett hvor man bor i Nepal er dette viktig. Religionens oppgave er å hjelpe oss til å skille mellom det gode og det onde. Vi må bekjempe korrupsjonen

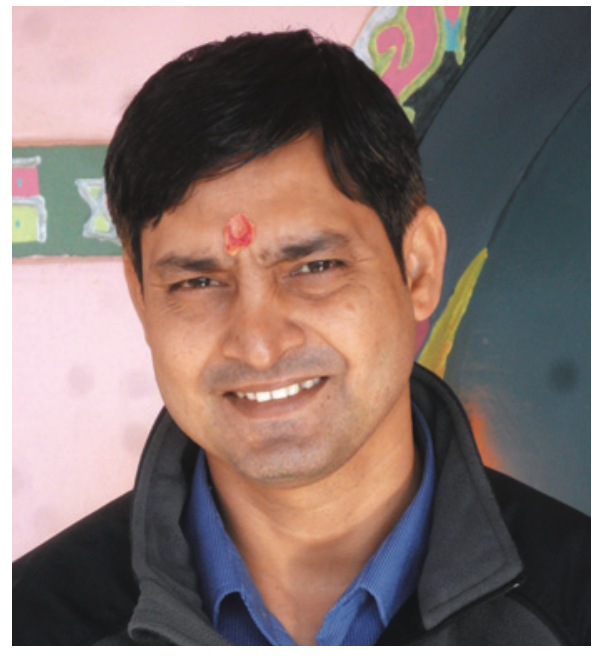

Suresh Ray Pant. Foto: Mons Lie

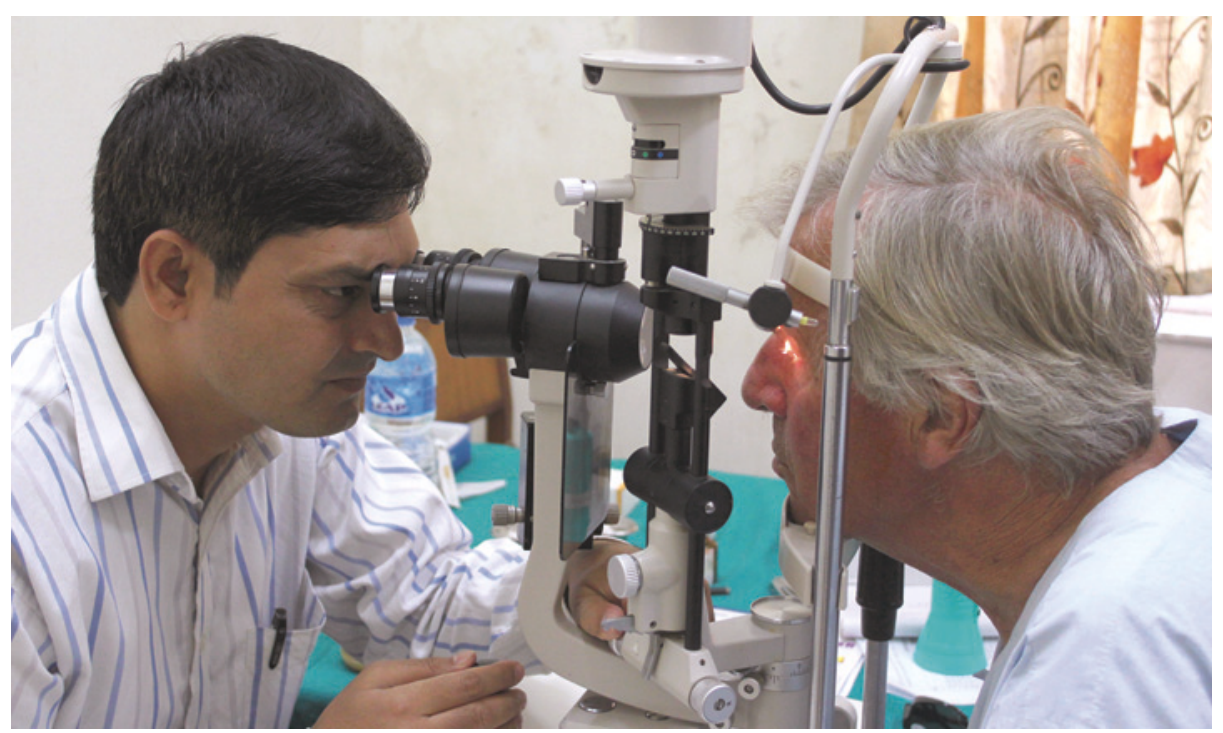

Suresh undersøker meg med spaltelampe. Foto: Svein Lie

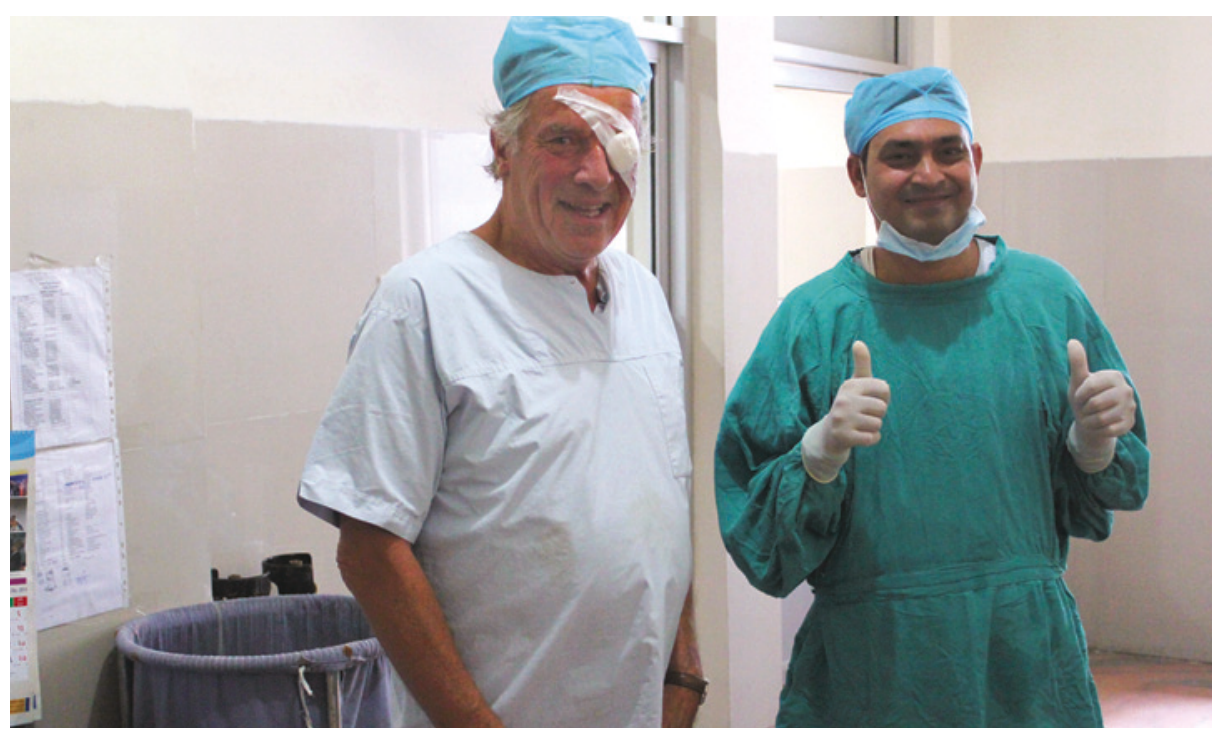

Mons Lie nyoperert med fornøyd operatør. Foto: Svein Lie 
som våre politikere er så gjennomsyret av. Vi må gi helsetjeneste til de fattige». Hinduer har respekt for dyr som kan være bolig for forfedres sjeler, og spiser dem nødig. «Apekattene på sykehusområdet var der før oss»), sa Suresh, da vi foreslo tiltak for å få dem fjernet. Dessuten mener mange de er tidligere Gurkha-krigere. De er ikke imot at apekattene forsvinner fra sykehusområdet, de er jo for så vidt en plage, men de forholder seg passive til tiltak fra norsk side rettet mot både dem og alle de herreløse hundene.

\section{$\emptyset$ yeoperasjonen}

På øyeklinikken, der vi fikk demonstrert undersøkelse med spaltelampe, ba jeg Suresh om å se på mitt venstre øye, som i noe tid var blitt tiltakende tåkete. Mitt høyre ble stæroperert for flere år siden på Ullevål sykehus. Han bekreftet at jeg hadde katarakt grad 2-3 og sa han godt kunne operere meg. Vi kjørte i to biler ned den slyngete smale fjellveien fra 2000 meters høyde mot Geta som ligger på havets nivå. På veien stoppet vi og drakk søt te med melk på en liten restaurant $i$ veikanten. Jeg sa da til Suresh at jeg hadde tenkt på hans tilbud og ville at han skulle operere meg. Han så en stund på meg før han sa: «Har du pass?» Da jeg bekreftet det, sa han: "Gi meg det, så du ikke stikker av». Vel fremme i Geta avtalte han å operere meg neste morgen. Det var dag før helligdag og få pasienter.

Neste morgen sto jeg i Getas registreringskø. Mitt reisefølge på to ble mine pårørende og gikk omsorgsfullt runden med meg blant tyvetalls pasienter og deres pårørende. Det ble gjort synstest, trykkmåling med Schiøtz' tonometer, blodtrykk og til sist ny spaltelampeundersøkelse av Suresh etter dilatasjon av pupillen. Etter alt dette så Suresh alvorlig på meg og sa: «Her har vi bare kunstige linser laget i Nepal.

De linsene som du ville fått $\mathrm{i}$ Norge, er for dyre for oss. Det er ikke dokumentert, men de er kanskje bedre enn våre. Vi har bare én facomaskin. Hvis den bryter sammen under operasjonen, det har hendt at den har gjort det, da må vi endre teknikken og legge større snitt, hente ut linsen manuelt og du får en ikke-foldbar linse. Om to dager skal du tilbake med fly til Norge. Under reisen har du ikke tilgang på medisinsk hjelp om det skulle oppstå komplikasjoner. Også jeg har komplikasjoner. Jeg synes kanskje du bør opereres i Oslo». Jeg svarte da at alt dette hadde jeg tenkt igjennom. Jeg ville fortsatt at han skulle operere meg. Det at han nå viste meg en nødutgang, slik at jeg kunne trekke meg uten at verken han eller jeg tapte ansikt, ga meg snarere økt tiltro til ham. Med et smil takket han for tilliten og sa han ville operere. Det gjorde klart inntrykk på ham at jeg dermed var sykehusets første utenlandske pasient, bortsett da fra inderne. Å oppleve hans og teamets varme omsorg, gleden da alt gikk bra, stoltheten over at sykehuset fikk sin velfortjente anerkjennelse, var for meg en stor opplevelse. Det var lett å si ja til at sykehuset la dette ut på sin facebook-side dagen etter operasjonen (7), da synsprøven viste at jeg så om mulig bedre på venstre enn på høyre øye.

Om kvelden kom nyheten på lokalradioen om at en norsk kirurg var vellykket operert på deres kjære sykehus. De gratulerte sykehuset, og sykehuset takket for tilliten.

\section{Mons Lie (f. 1938)}

er dr.med. og spesialist i generell kirurgi, i karkirurgi og thoraxkirurgi. Han er pensjonist og styremedlem i stiftelsen InFiL.

Forfatter har fylt ut ICMJE-skjemaet og oppgir ingen interessekonflikter.

Litteratur

Store norske leksikon. Nepal. https://snl.no/Nepal (16.1.2015)

2. The epidemiology of blindness in Nepal. Report of the 1981 Nepal Blindness Survey. Chelsea: The Seva Foundation, 1988.

3. Nepal Netra Jyoti Sangh. Vision 2020. http://nnjs.org.np/index/page/ coordination-structure (22.1.2015)

4. Pokhrel RP. Reaching the unreached. Three decades of struggle in Nepal. Katmandu: Everest Nursing Home, 2003.

5. Vision 2020. The right to sight. Katmandu: Nepal Netra Jyoti Sangh, 2012

6. Annual report year 2013. Kailali: Geta Eye Hospital, 2014.

7. Geta Eye Hospital. Facebook. www.facebook.com/ pages/Geta-Eye-Hospital/184009618307838 (22.1.2015).

Mottatt 13.11. 2014, første revisjon innsendt 6.1. 2015, godkjent 2.2. 2015. Redaktør: Siri Lunde Strømme. 